\title{
Seed Germination and Storage of the Endangered Species Manglietia crassipes Y. W. Law (Magnoliaceae)
}

\author{
Ai-Hua Wang ${ }^{1,2}{ }^{\mathbb{D}}$, Xiao-Ling Yu ${ }^{2}$, Yan-Yan Liu ${ }^{1}$, Shu-Gang Chen ${ }^{2}$ and Fa-Guo Wang ${ }^{2, *} \mathbb{C}$ \\ 1 Key Laboratory of Environment Change and Resources Use in Beibu Gulf, Nanning Normal University, \\ Ministry of Education, Nanning 530001, China; wangah@scbg.ac.cn (A.-H.W.); \\ liuyanyan5000@163.com (Y.-Y.L.) \\ 2 Key Laboratory of Plant Resources Conservation and Sustainable Utilization, South China Botanical Garden, \\ Chinese Academy of Sciences, Guangzhou 510650, China; yuxl@scbg.ac.cn (X.-L.Y.); \\ shugangchen@163.com (S.-G.C.) \\ * Correspondence: wangfg@scbg.ac.cn
}

check for

updates

Citation: Wang, A.-H.; Yu, X.-L.; Liu, Y.-Y.; Chen, S.-G.; Wang, F.-G. Seed Germination and Storage of the Endangered Species Manglietia crassipes Y. W. Law (Magnoliaceae). Horticulturae 2021, 7, 42. https:// doi.org/10.3390/horticulturae7030042

Received: 18 January 2021

Accepted: 24 February 2021

Published: 28 February 2021

Publisher's Note: MDPI stays neutral with regard to jurisdictional claims in published maps and institutional affiliations.

Copyright: (c) 2021 by the authors. Licensee MDPI, Basel, Switzerland. This article is an open access article distributed under the terms and conditions of the Creative Commons Attribution (CC BY) license (https:/ / creativecommons.org/licenses/by/ $4.0 /)$.
Abstract: Manglietia crassipes, a critically endangered species narrowly distributed on Mount Dayao in Guangxi, China, is also a species of ornamental interest whose variability has not been explored. Key factors leading to its endangerment have also not been studied. Here, two experiments were conducted to test the effects of different plant growth regulators and different storage conditions on germination characteristics of M. crassipes seeds. Fruit morphology was measured, and germination characteristics of fresh mature seeds were tested in order to assess natural seed vigor. Seeds were soaked in distilled water (control), or gibberellic acid $\left(\mathrm{GA}_{3}\right)$, 6-benzylaminopurine (6-BA) or indoleacetic acid (IAA) solutions of different concentrations, for $48 \mathrm{~h}$ to determine their effects on seed germination. In addition, the effects of different seed storage conditions (constant $4{ }^{\circ} \mathrm{C},-7^{\circ} \mathrm{C}$, $-20{ }^{\circ} \mathrm{C}$, or $25{ }^{\circ} \mathrm{C}$ for 100 days, wet stratification at $4{ }^{\circ} \mathrm{C}$ for 100 days) on seed germination were investigated. Results showed that the abortive rate of the mature fruits was high $(28.9 \%)$ and fresh natural seeds had a low germination rate $(\mathrm{G})$ and germination index (GI). Seed germination was inhibited with 6-BA at all concentrations, but only at less than $100 \mathrm{~m} \cdot \mathrm{L}^{-1}$ IAA; otherwise, IAA slightly promoted seed germination. $\mathrm{GA}_{3}$ broke seed dormancy and significantly accelerated seed germination by improving G, GI and initial germination time (IGT), especially over $2500 \mathrm{mg} \cdot \mathrm{L}^{-1}$. The viability of seeds declined no matter how they were stored. However, $4{ }^{\circ} \mathrm{C}$ wet stratification storage was preferable for seed vigor and germination power. Our results suggest that the high abortive rate of fruits, low germination of the natural seed, seed dormancy and its intolerance to storage, contributed to the endangerment of $M$. crassipes. $\mathrm{GA}_{3}$ can break M. crassipes seed dormancy, which can be a benefit for future ornamental breeding and further protection or conservation.

Keywords: Manglietia crassipes; endangered plant; seed germination; seed storage; protection

\section{Introduction}

Manglietia crassipes Y. W. Law (family: Magnoliaceae) is an endemic tree of China. Manglietia is comprised of about 40 species distributed in tropical and subtropical Asia. In China, there are 27 to 29 species (15 to 17 of which are endemic), mostly distributed in the southern area of the Yangtze River [1]. M. crassipes is a small-sized evergreen tree about $4 \mathrm{~m}$ tall. It was first described in 1982, while a specimen of it was first collected in 1959 [2]. With white, fragrant flowers, dense branches and leaves, and a popular aesthetic, it is commonly used as an ornamental tree [3]. However, it only grows in forests of altitudes of about $1300 \mathrm{~m}$ on Mount Dayao, Guangxi, China. The species was listed as critically endangered in the China Species Red List [4] owing to its restricted distribution. Our field investigation found that there were 100-1000 trees in total on Mount Dayao, mostly scattered. Thus, it is urgent to study the seed propagation of this species to prevent it from dying out. 
Magnoliaceae is one of the most threatened angiosperm families, in which several species are endangered and at risk of extinction [5]. Magnoliaceae plants in the wild reproduce through seeds, and much previous research has focused on the mechanisms underlying seed propagation, such as seed collection, preparation and storage, and nursery selection, and especially on seed dormancy and germination [3,5-19].

In Manglietia, studies attempting to understand seed germination and dormancy have been carried out for some species such as M. grandis [20-22] and M. patungensis [23,24]. However, there is no information on seed propagation of the lesser-known species $M$. crassipes, which is now facing the threat of extinction. In order to prevent it from extinction, we should understand the mechanisms of seed propagation for improving artificial propagation technology. Here, we carried out a series of seed germination experiments to test the vigor of the fresh seeds. Meanwhile, a series of concentration gradient experiments using the plant growth regulators $\mathrm{GA}_{3}, 6-\mathrm{BA}$ and IAA, as well as different seed storage conditions, were applied to understand their effects on germination and dormancy of M. crassipes.

\section{Materials and Methods}

\subsection{Seed Source}

Mature follicles of M. crassipes (some fruits dehisced naturally exposing red-oily arillate) were collected from the Nature Reserve of Yinsha $\left(24^{\circ} 9^{\prime} 41^{\prime \prime} \mathrm{N}, 110^{\circ} 13^{\prime} 44^{\prime \prime} \mathrm{E}\right.$; $1161 \mathrm{~m}$ a.s.l.) on Mount Dayao (Jinxiu County, Guangxi province, China). Considering that seed germination may be influenced by individual differences within species, seed collection times, storage methods and plant growth regulator treatment, we collected 103 fruits from eight randomly distributed trees of $M$. crassipes on 29 August 2011. Detailed local information for the eight trees is presented in Table 1. The developmental characters of fruit were observed and recorded. Fruits were collected and threshed naturally in the laboratory. Seeds were then washed manually [25]. After sterilizing seeds with $75 \%$ ethanol for $30 \mathrm{~s}$, they were quickly rinsed with sterile water three times and dried with absorbent paper. Sterilized seed were stored as described below for 100 days.

Table 1. Collection locations of eight trees of Manglietia crassipes.

\begin{tabular}{clll}
\hline Tree & Longitude & Latitude & Elevation (m) \\
\hline $\mathrm{A}$ & $110^{\circ} 13^{\prime} 50^{\prime \prime} \mathrm{E}$ & $24^{\circ} 09^{\prime} 58^{\prime \prime} \mathrm{N}$ & 1206 \\
$\mathrm{~B}$ & $110^{\circ} 14^{\prime} 36^{\prime \prime} \mathrm{E}$ & $24^{\circ} 10^{\prime} 29^{\prime \prime} \mathrm{N}$ & 1181 \\
$\mathrm{C}$ & $110^{\circ} 14^{\prime} 35^{\prime \prime} \mathrm{E}$ & $24^{\circ} 10^{\prime} 26^{\prime \prime} \mathrm{N}$ & 1098 \\
$\mathrm{D}$ & $110^{\circ} 14^{\prime} 38^{\prime \prime} \mathrm{E}$ & $24^{\circ} 10^{\prime} 11^{\prime \prime} \mathrm{N}$ & 1159 \\
$\mathrm{E}$ & $110^{\circ} 14^{\prime} 38^{\prime \prime} \mathrm{E}$ & $24^{\circ} 10^{\prime} 08^{\prime \prime} \mathrm{N}$ & 1177 \\
$\mathrm{~F}$ & $110^{\circ} 14^{\prime} 35^{\prime \prime} \mathrm{E}$ & $24^{\circ} 10^{\prime} 13^{\prime \prime} \mathrm{N}$ & 1172 \\
$\mathrm{G}$ & $110^{\circ} 13^{\prime} 45^{\prime \prime} \mathrm{E}$ & $24^{\circ} 09^{\prime} 48^{\prime \prime} \mathrm{N}$ & 1182 \\
$\mathrm{H}$ & $110^{\circ} 13^{\prime} 44^{\prime \prime} \mathrm{E}$ & $24^{\circ} 09^{\prime} 41^{\prime \prime} \mathrm{N}$ & 1161 \\
\hline
\end{tabular}

\subsection{Character Traits of Fruits and Seeds}

The length and diameter of the carpopodium and the length and width of each fruit and carpel were measured directly using a vernier calliper. Carpels were counted from 20 random fruits. Developing seeds and abortive seeds of each carpel were counted, and the abortion rate was calculated. The mean size, including length, width and thickness of seeds was measured from 20 random seeds using a vernier calliper.

Main characteristics of seeds, including thousand seed weight and seed vigor, were measured through the "hundredseed methods" [26], and the 2,3,5-triphenyl-2H-tetrazolium chloride (TTC) method. Water imbibition of newly matured seeds (i.e., seeds recently removed from arils, 20 seeds, four replicates) was evaluated by soaking in distilled water and weighing every $2 \mathrm{~h}$ at $25^{\circ} \mathrm{C}$ for the first $12 \mathrm{~h}$ and then at $12 \mathrm{~h}$ intervals until saturated. Moisture content of the seeds (20 seeds, four replicates) was measured as well as their fresh 
weights and dry weights. Seeds were dried in an incubator for about $24 \mathrm{~h}$ at $103{ }^{\circ} \mathrm{C} \pm 2{ }^{\circ} \mathrm{C}$, until weight no longer changed, following [27].

\subsection{Germination Tests under Different Plant Growth Regulators}

The effect of gibberellic acid $\left(\mathrm{GA}_{3}\right)$ on dormancy and germination of $M$. crassipes seeds was studied as follows: seeds were soaked in water at $35^{\circ} \mathrm{C}$ for $24 \mathrm{~h}$ before putting them in $0,200,500,1000,1500,2000$ or $2500 \mathrm{mg} \cdot \mathrm{L}^{-1} \mathrm{GA}_{3}$, or $0,20,50,100,200,500$ or $1000 \mathrm{mg} \cdot \mathrm{L}^{-1}$ 6-benzylaminopurine (6-BA) or indoleacetic acid (IAA) for $48 \mathrm{~h}$ at $25^{\circ} \mathrm{C}$. They were then washed with water 3-5 times. Then, three replicates of 50 seeds each were randomly selected, placed in a culture dish and transferred to a growth cabinet PQX-260B for germination. Similarly, seeds were soaked in water for $48 \mathrm{~h}$ and transferred to the growth chamber. Growth conditions of the cabinet were a $12 \mathrm{~h} / 12 \mathrm{~h}$ light/dark photoperiod at $20{ }^{\circ} \mathrm{C}$ in the dark and $25{ }^{\circ} \mathrm{C}$ in the light, a relative humidity of $80 \pm 5 \%$ and an illumination intensity of $1500 \mathrm{~lx}$.

The germination of the seeds was monitored daily until germination ceased. Monitored parameters included the initial germination time (IGT), germination percentage (G), germination power (GP) and germination index (GI). For each replication in each treatment, the germination percentage was calculated as $G=(n / N) \times 100$, where $n$ is the number of germinated seeds and $\mathrm{N}$ is the total number of seeds. The GI percentage was calculated as:

$$
\mathrm{GI}=\sum_{\mathrm{i}=1}^{n} \frac{\mathrm{Gi}}{\mathrm{Di}} \times 100 \%
$$

where $\mathrm{Gi}$ is the number of germinated seeds on the ith day and $\mathrm{Di}$ is the number of days. The germination power $(\mathrm{GP})$ was calculated as $\mathrm{GP}=(\mathrm{Nm} / \mathrm{N}) \times 100$ where $\mathrm{Nm}$ represents the number of germinated seeds on the day when counts of germinated seeds reached the maximum, and $\mathrm{N}$ is the total number of seeds.

\subsection{Viability and Storage}

To identify suitable storage conditions and understand seed viability characteristics, three tests were conducted. In the first test, fresh, clean and disinfected seeds were packed in sealed polyethylene bags (approximately 1000 seed / bag) and stored at $25^{\circ} \mathrm{C}$ for 100 days. In the second test, seeds were packed in sealed polyethylene bags and stored at constant temperatures of $4,-7$ or $-20^{\circ} \mathrm{C}$ for 100 days. The third test followed the same approach with seed stratified at $4{ }^{\circ} \mathrm{C}$ in moist sand for 100 days. Seed IGT, G, GP, and GI were assessed as described above. Seed viability was also determined using the TTC method. The procedure of the TTC method was as follows: 100 randomly selected seeds were soaked in $35^{\circ} \mathrm{C}$ water for $24 \mathrm{~h}$ to fully imbibe. Then, each seed was cut in half along the center, placing one half in a culture dish and adding $0.5 \%$ TTC $(w / v)$ solution before placing in an incubator in the dark at $35^{\circ} \mathrm{C}$ for $24 \mathrm{~h}$. The other half was boiled in water for $5 \mathrm{~min}$ to kill the embryo, and the same treatment was used as the control. After $24 \mathrm{~h}$, the TTC solution was poured out, the seeds were washed with distilled water one to two times, and the color of the embryo was observed. All seeds with a red embryo were living seeds. The number of seeds with a red embryo were counted, and then the percentage seed vigor (with red color) was calculated.

\subsection{Data Analysis}

To compare the different effects of the three plant growth regulators on fresh and mature seed germination, and to determine the effect of different storage conditions on seed germination and viability, analysis of variance was used with multiple comparisons by Fisher's Least Significant Difference Test at $p<0.05$ using SPSS (Statistical Product and Service Solutions, version 20). Means and standard error (SE) of each treatment were calculated. 


\section{Results}

\subsection{Basic Characteristics of Fruits and Seeds}

There were 20 incompletely developed fruit among the 103 fruits collected (19.42\%). The length of the carpopodium ranged from 4.2 to $6.5 \mathrm{~cm}$ (mean $5.2 \mathrm{~cm}$ ). The diameter of the carpopodium was 7-10 $\mathrm{mm}$ (mean $8.4 \mathrm{~mm}$ ). The mean length of the fruit was $5-7 \mathrm{~cm}$ (mean $5.2 \mathrm{~cm}$ ), and its width was $3.6-5.0 \mathrm{~cm}$ (mean $4.4 \mathrm{~cm}$ ). The length of the carpel was $1.1-2.3 \mathrm{~cm}$ (mean $1.8 \mathrm{~cm}$ ) and the width was $0.6-1.3 \mathrm{~cm}$ (mean $1.0 \mathrm{~cm}$ ). There was an average of 33 carpels, 210 developed seeds and 85 aborted seeds among the randomly selected 20 fruit, which means the abortion percentage was $28.9 \%$. Detailed information is shown in Table 2. Appearance of the seed is shown in Figure 1.

Table 2. Basic characters of fruits from Manglietia crassipes.

\begin{tabular}{cllll}
\hline Numbered Fruit & Number of Carpels & $\begin{array}{l}\text { Number of } \\
\text { Developed Seeds }\end{array}$ & $\begin{array}{l}\text { Numbers of } \\
\text { Aborted Seeds }\end{array}$ & Abortion Rate \\
\hline 1 & 37 & 267 & 25 & 0.085616 \\
2 & 37 & 337 & 52 & 0.133676 \\
3 & 36 & 281 & 48 & 0.145897 \\
4 & 36 & 266 & 47 & 0.15016 \\
5 & 33 & 225 & 42 & 0.157303 \\
6 & 34 & 219 & 81 & 0.27 \\
7 & 32 & 202 & 78 & 0.278571 \\
8 & 25 & 142 & 58 & 0.29 \\
9 & 36 & 227 & 98 & 0.301538 \\
10 & 30 & 197 & 86 & 0.303887 \\
11 & 32 & 199 & 87 & 0.304196 \\
12 & 39 & 264 & 118 & 0.308901 \\
13 & 32 & 183 & 82 & 0.309434 \\
14 & 30 & 150 & 73 & 0.327354 \\
15 & 31 & 199 & 98 & 0.329966 \\
16 & 30 & 165 & 82 & 0.331984 \\
17 & 31 & 193 & 99 & 0.339041 \\
18 & 27 & 125 & 84 & 0.401914 \\
19 & 42 & 241 & 189 & 0.439535 \\
20 & 35 & 135 & 176 & 0.565916 \\
Mean value & 33.25 & 210.85 & 85.15 & 0.288745 \\
\hline
\end{tabular}

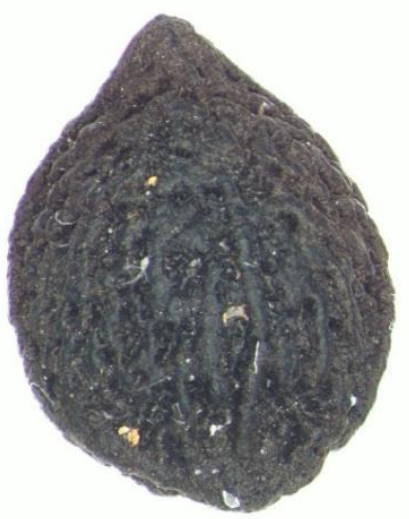

Figure 1. Seed appearance of Manglietia crassipes.

Seed size (including the exotesta) of $M$. crassipes was 5-7 $\times 4-5 \mathrm{~mm}$. Its thousand seed weight was $36.6 \mathrm{~g}$ (derived from the mean weight of 100 seeds with eight replicates at $3.66 \mathrm{~g})$, and the coefficient of variation $(\mathrm{CV})$ was 1.524 , which is $\leq 4.0$. 


\subsection{Moisture Content and Water Imbibition}

The mean moisture content of fully developed seeds was $9.80 \%$, with a standard deviation (SD) of $0.24 \%$, SE of $0.12 \%$, and CV of 2.5 . Relative moisture content of seeds was $31.85 \% \pm 0.87 \%$, which was much higher than that of Magnolia punduana $(26.43 \% \pm 0.31 \%)$, as has been reported [19].

Seeds absorbed water increasingly through time until reaching saturation at about $84 \mathrm{~h}$ and then remained constant. Seeds absorbed water quickly during the first $2 \mathrm{~h}$, after which, the absorption speed decreased gradually until saturation.

\subsection{Germination Tests}

Germination percentage (G), GP, GI, and its IGT of the seeds treated with GA, 6-BA, and IAA were calculated, and the results are shown in Table 3 and Table S1. Germination with $\mathrm{GA}_{3}$ treatment was significantly different from that of the other treatments and the control. G of 6-BA was also greater than IAA at $p \pm \leq 0.05$ and the control was equal to both. Thus, we focused on the analyses of effects from $\mathrm{GA}_{3}$.

Table 3. Multiple comparisons of effects of $\mathrm{GA}_{3}, 6-\mathrm{BA}$ and IAA treatment on initial germination time (IGT), germination percentage $(\mathrm{G})$, germination power (GP), and germination index (GI). SE is standard error and LSD is Fisher's Least Significant Difference at $P \leq 0.05$ and 0.01 .

\begin{tabular}{|c|c|c|c|c|}
\hline \multirow{2}{*}{ Plant Growth Regulators } & \multirow{2}{*}{ Means IGT } & \multirow{2}{*}{ SE } & \multicolumn{2}{|c|}{ LSD } \\
\hline & & & 0.05 & 0.01 \\
\hline $\mathrm{GA}_{3}$ & 15.78 & 1.00 & a & A \\
\hline $6-\mathrm{BA}$ & 46.72 & 8.74 & $\mathrm{~b}$ & $\mathrm{~B}$ \\
\hline IAA & 44.94 & 6.39 & $\mathrm{~b}$ & B \\
\hline Control & 46.33 & 2.08 & $\mathrm{~b}$ & $\mathrm{~B}$ \\
\hline \multirow{2}{*}{ Plant growth regulators } & \multirow{2}{*}{$\mathrm{G}(\%)$} & \multirow{2}{*}{ SE } & \multicolumn{2}{|c|}{ LSD } \\
\hline & & & 0.05 & 0.01 \\
\hline $\mathrm{GA}_{3}$ & 66 & 0.10 & a & A \\
\hline $6-\mathrm{BA}$ & 11 & 0.045 & $c$ & B \\
\hline IAA & 16 & 0.046 & bc & B \\
\hline Control & 16 & 0.053 & bc & $\mathrm{B}$ \\
\hline \multirow{2}{*}{ Plant growth regulators } & \multirow{2}{*}{ GP } & \multirow{2}{*}{ SE } & \multicolumn{2}{|c|}{ LSD } \\
\hline & & & 0.05 & 0.01 \\
\hline $\mathrm{GA}_{3}$ & 0.26 & 0.11 & a & A \\
\hline $6-\mathrm{BA}$ & 0.068 & 0.023 & $\mathrm{~b}$ & B \\
\hline IAA & 0.098 & 0.041 & $\mathrm{~b}$ & B \\
\hline Control & 0.08 & 0.02 & $\mathrm{~b}$ & $\mathrm{~B}$ \\
\hline \multirow{2}{*}{ Plant growth regulators } & \multirow{2}{*}{ GI } & \multirow{2}{*}{ SE } & \multicolumn{2}{|c|}{ LSD } \\
\hline & & & 0.05 & 0.01 \\
\hline $\mathrm{GA}_{3}$ & 1.51 & 0.30 & $\mathrm{a}$ & A \\
\hline 6-BA & 0.11 & 0.04 & $\mathrm{~b}$ & B \\
\hline IAA & 0.15 & 0.05 & $\mathrm{~b}$ & B \\
\hline Control & 0.15 & 0.04 & $\mathrm{~b}$ & B \\
\hline
\end{tabular}

For the control, the germination rate was low with a mean of 0.16 ; mean GI was 0.149 and IGT was $46.3 \mathrm{~h}$. The IGT of seeds treated with $\mathrm{GA}_{3}$ was the same $(15.8 \mathrm{~h})$ at all $\mathrm{GA}_{3}$ concentrations and was much earlier than that of the control (Table 3). The G and GI of $\mathrm{GA}_{3}$-treated seeds were higher than those of the control (Figure 2, Table 3). The GP and GI were significantly different from $\mathrm{GA}_{3}$, and also between $\mathrm{GA}_{3} \mathrm{~A} 1$ and $\mathrm{A} 6$, while no significant difference existed between the two adjacent groups, e.g., A1 and A2, A2 and A3 (Table 4). These results indicate that $\mathrm{GA}_{3}$ significantly affected seed germination compared with the control, and the effects of $\mathrm{GA}_{3}$ gradually increased with increasing concentration till $2500 \mathrm{mg} \cdot \mathrm{L}^{-1}$. All of these results suggest that $\mathrm{GA}_{3}$ can break the seed dormancy of $M$. crassipes and promote seed germination. 


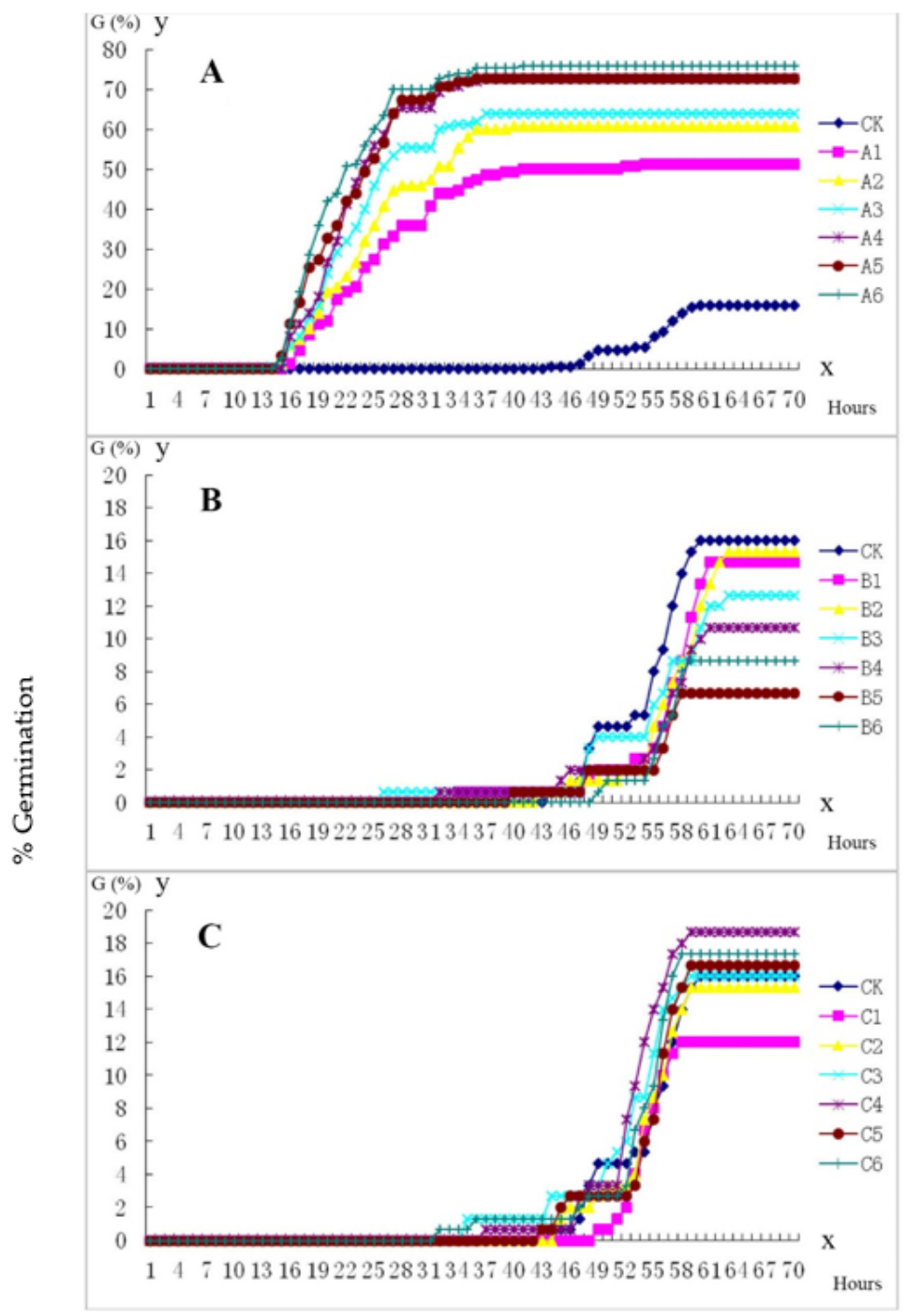

Hours

Figure 2. Seed germination rate changed when they were soaked in different concentrations of GA $_{3}$, 6-BA and IAA. (A) Germination rate with $\mathrm{GA}_{3}$ treatment. A1-A6: 200, 500, 1000, 1500, 2000, $2500 \mathrm{mg} \cdot \mathrm{L}^{-1} \mathrm{GA}_{3}$, respectively. (B) Germination rate with 6-BA treatment. B1-B6: 20, 50, 100, 200, $500,1000 \mathrm{mg} \cdot \mathrm{L}^{-1}$ 6-BA, respectively. (C) Germination rate with IAA treatment. C1-C6: 20, 50, 100, 200, 500, and $1000 \mathrm{mg} \cdot \mathrm{L}^{-1}$ IAA, respectively. CK: water control.

Although the type of plant growth regulator was the main source of difference for the IGT, G, GP and GI, we observed some concentration gradient effects on GP and GI (Supplemental Tables S2-S5). Although the IGT of seeds treated with 6-BA was the same as those of the control, G and GI were lower (Figure 2B and Table 3). There were no significant differences observed in G and GI between the control and 6-BA. These results indicate that 6-BA can slightly inhibit seed germination.

Seed germination responded to IAA in a more complex manner. The G of C3 (100 mg. $\mathrm{L}^{-1}$ ) IAA was the same as that of ck (Figure 2C). When the concentration was lower than C3, IAA inhibited seed germination. The less IAA the lower the germination rate until $\mathrm{C} 1\left(20 \mathrm{mg} \cdot \mathrm{L}^{-1}\right)$, in which the least seeds germinated. However, IAA can slightly improve seed germination if its concentration is higher than that of $\mathrm{C} 3$ (Figure 2C).

\subsection{Viability and Storage}

Based on the above results, all stored seeds were soaked in $2500 \mathrm{mg} \cdot \mathrm{L}^{-1} \mathrm{GA}_{3}$ to test the effects of storage conditions on seed viability. Multiple comparisons and analysis 
of variance were conducted, and the results are presented in Table 5. The mortality of seeds not stored (unstained) was $8 \%$, while that of seeds stratified at $4{ }^{\circ} \mathrm{C}$ in moist sand, at constant temperature $\left(4,-7\right.$ or $\left.-20^{\circ} \mathrm{C}\right)$, and at $25^{\circ} \mathrm{C}$, were $36,46,53,59$ and $81 \%$, respectively. Significant differences at $p<0.05$ and $<0.01$ were observed for the mortality between each other, but with no significant difference between $-7{ }^{\circ} \mathrm{C}$ and $-20^{\circ} \mathrm{C}$.

Table 4. Multiple comparisons for the effects of increasing concentrations of $\mathrm{GA}_{3}$ on GP and GI. A1-A6 are 200, 500, 1000, 1500, 2000, $2500 \mathrm{mg} \cdot \mathrm{L}^{-1} \mathrm{GA}_{3}$, respectively. SE is standard error and LSD is Fisher's Least Significant Difference at $p \leq 0.05$ and 0.01 .

\begin{tabular}{|c|c|c|c|c|}
\hline \multirow{2}{*}{ Concentration Gradient } & \multirow{2}{*}{ Mean of GP } & \multirow{2}{*}{ SE } & \multicolumn{2}{|c|}{ LSD } \\
\hline & & & 0.05 & 0.01 \\
\hline A1 & 0.12 & 0.07 & $\mathrm{a}$ & A \\
\hline A2 & 0.19 & 0.03 & $\mathrm{ab}$ & $\mathrm{ABC}$ \\
\hline A3 & 0.24 & 0.05 & $a b c$ & $\mathrm{ABC}$ \\
\hline A4 & 0.27 & 0.04 & $\mathrm{bc}$ & $\mathrm{ABC}$ \\
\hline A5 & 0.33 & 0.03 & bc & $\mathrm{ABC}$ \\
\hline A6 & 0.42 & 0.07 & $c$ & C \\
\hline Control & 0.08 & 0.02 & $a b$ & $\mathrm{ABC}$ \\
\hline \multirow{2}{*}{ Concentration Gradient } & \multirow{2}{*}{ Mean of GI } & \multirow{2}{*}{ SE } & \multicolumn{2}{|c|}{ LSD } \\
\hline & & & 0.05 & 0.01 \\
\hline $\mathrm{A} 1$ & 1.06 & 0.12 & $\mathrm{a}$ & $\mathrm{A}$ \\
\hline $\mathrm{A} 2$ & 1.30 & 0.17 & $\mathrm{ab}$ & $\mathrm{ABC}$ \\
\hline A3 & 1.45 & 0.11 & $a b c$ & $\mathrm{ABC}$ \\
\hline A4 & 1.67 & 0.18 & $\mathrm{bc}$ & $\mathrm{BC}$ \\
\hline A5 & 1.74 & 0.04 & $\mathrm{bc}$ & $\mathrm{BC}$ \\
\hline A6 & 1.86 & 0.09 & $\mathrm{c}$ & $\mathrm{C}$ \\
\hline Control & 0.15 & 0.04 & $\mathrm{~d}$ & $\mathrm{D}$ \\
\hline
\end{tabular}

Table 5. Multiple comparisons of seed vigor stored at different conditions. SE is standard error and LSD is Fisher's Least Significant Difference at $P \leq 0.05$ and 0.01 .

\begin{tabular}{|c|c|c|c|c|}
\hline \multirow{2}{*}{ Stored Conditions } & \multirow{2}{*}{ Unstained } & \multirow{2}{*}{ SE } & \multicolumn{2}{|c|}{ LSD } \\
\hline & & & 0.05 & 0.01 \\
\hline Black control & 8 & 1.63 & $\mathrm{f}$ & $\mathrm{E}$ \\
\hline Indoor temperature, dry, 100 days & 81 & 1.00 & a & A \\
\hline $4^{\circ} \mathrm{C}$ cold stratification, 100 days & 36 & 2.83 & e & $\mathrm{D}$ \\
\hline $4^{\circ} \mathrm{C}$, dry, room, 100 days & 46 & 2.58 & $\mathrm{~d}$ & $\mathrm{C}$ \\
\hline$-7^{\circ} \mathrm{C}$, dry, room, 100 days & 53 & 1.00 & c & $\mathrm{BC}$ \\
\hline$-20^{\circ} \mathrm{C}$, dry, room, 100 days & 59 & 1.00 & $\mathrm{~b}$ & $\mathrm{~B}$ \\
\hline \multirow{2}{*}{ Stored Conditions } & \multirow{2}{*}{$\operatorname{Red}(\%)$} & \multirow{2}{*}{ SE } & \multicolumn{2}{|c|}{ LSD } \\
\hline & & & 0.05 & 0.01 \\
\hline Black control & 73 & 2.52 & a & A \\
\hline Indoor temperature, dry, 100 days & 6 & 1.15 & e & $\mathrm{E}$ \\
\hline $4^{\circ} \mathrm{C}$ cold stratification, 100 days & 37 & 1.91 & $\mathrm{~b}$ & $\mathrm{~B}$ \\
\hline $4^{\circ} \mathrm{C}$, dry, room, 100 days & 27 & 1.00 & c & $\mathrm{C}$ \\
\hline$-7^{\circ} \mathrm{C}$, dry, room, 100 days & 17 & 1.00 & $\mathrm{~d}$ & $\mathrm{D}$ \\
\hline$-20^{\circ} \mathrm{C}$, dry, room, 100 days & 24 & 1.63 & c & $\mathrm{C}$ \\
\hline \multirow{2}{*}{ Stored Conditions } & \multirow{2}{*}{ Light red } & \multirow{2}{*}{ SE } & \multicolumn{2}{|c|}{ LSD } \\
\hline & & & 0.05 & 0.01 \\
\hline Black control & 19 & 1.00 & $\mathrm{~b}$ & B \\
\hline Indoor temperature, dry, 100 days & 13 & 1.00 & c & $\mathrm{B}$ \\
\hline $4^{\circ} \mathrm{C}$ cold stratification, 100 days & 27 & 1.91 & a & A \\
\hline $4^{\circ} \mathrm{C}$, dry, room, 100 days & 27 & 3.00 & a & A \\
\hline$-7^{\circ} \mathrm{C}$, dry, room, 100 days & 30 & 1.15 & a & A \\
\hline$-20^{\circ} \mathrm{C}$, dry, room, 100 days & 17 & 2.52 & $\mathrm{bc}$ & $\mathrm{B}$ \\
\hline
\end{tabular}

Note: unstained seeds indicated they were dead; Red indicated all of them can germinate; Light red presented seeds have weak germination vigor.

The seed vigor (red in TTC) in the control and stored at $4{ }^{\circ} \mathrm{C}$ in moist sand and at constant temperatures $\left(4^{\circ} \mathrm{C},-7^{\circ} \mathrm{C}\right.$, or $\left.-20^{\circ} \mathrm{C}\right)$ were $73,37,27,24$ and $6 \%$, respectively, 
and significant differences were observed between each storage method. Many seeds were found to exhibit weak germination viability (pink in TTC) under $4{ }^{\circ} \mathrm{C}$ moist sand stratification and constant temperature $\left(4,-7\right.$ or $\left.-20^{\circ} \mathrm{C}\right)$ conditions. Furthermore, significant differences in the percentage of weak seeds were observed between the group $\left(4^{\circ} \mathrm{C}\right.$ moist sand stratification, $4{ }^{\circ} \mathrm{C}$, and $\left.-7{ }^{\circ} \mathrm{C}\right)$ and another group $\left(-20^{\circ} \mathrm{C}, 25^{\circ} \mathrm{C}\right.$, and the control).

From these results, we conclude that the seed germination viability of $M$. crassipes will be weakened no matter the storage method used. Therefore, it is important to collect and sow the seeds at the proper time. However, if seeds must be stored, $4{ }^{\circ} \mathrm{C}$, moist sand stratification is the best method owing to the lower mortality and higher complete germination viability, and the second best method is $4{ }^{\circ} \mathrm{C}$ dry storage.

\section{Discussion}

\subsection{Low Vigor of Seeds in the Wild Maybe the Major Reason for Endangered Status}

Underdeveloped embryos at maturity, impermeability of the seed coat, and germination inhibitors are major reasons causing dormancy of Magnoliaceae seeds [10,13,14,16,17,19,23,28-33]. Seed morphophysiological dormancy was found in the species Manglietia patungensis, and the main reasons for seed dormancy were underdeveloped embryos and some germination inhibitors [23]. Seed dominancy varies among different species [7]. According to our results, physiological dormancy was indicated in $M$. crassipes by the different effects of $\mathrm{GA}_{3}$, 6-BA and IAA on seed germination. Some germination inhibitors may exist in seeds; 6-BA may promote inhibition, while $\mathrm{GA}_{3}$ can relieve inhibition and induce seeds to germinate, breaking dormancy. Whether there was morphological dormancy in $M$. crassipes needs more study because all seeds used in our research were mature seeds whose pericarp and testa were removed to exclude physical barriers to germination. Detailed seeds structures were not studied here.

The black control seeds had much lower germination rates than the stored seeds, but the stored seeds had lower viability. Under natural conditions, seeds are often found hanging on the fruit by a filar petiole after the follicle dehisces. Animals such as birds and rodents eat the exposed fleshy seeds, attracted by their vivid red color and sweet smell. Being swallowed by birds benefits seed transmission because the enteric canal and gastric acid of birds does not hurt the hard episperm or the inner embryo. However, if bitten by rodents, seeds are destroyed and lose their germination viability. Furthermore, seeds usually become moldy caused by the outer covered fleshy sarcotesta and its long dormancy of several months after falling from a tree. Therefore, seed germination is restricted in the wild and live seedlings are rare near adult trees of $M$. crassipes.

\subsection{High Abortion Rate of the Fruit may Be a Potential Adaptation to Changed Environment}

The high abortion rate of the fruit $(28.9 \%)$ in $M$. crassipes probably is a potential adaptation to environmental change. It is usual for plants to selectively abort seeds (called "Selective Abortion Phenomenon") in angiosperms [34]. Gene and resource limitations are the main reasons for selective abortion, and seeds or fruits with weak genotypes are abandoned, which not only improves the conformity between parents and offspring but also increases the diffusion rate of seeds or fruits [34]. The restricted distribution of $M$. crassipes, together with its low seed diffusion and germination rate, make it likely to adopt selective abortion to improve its adaption to the environment. Additional research on the blooming sequence, pollen type, pollination system and pollinators is required to understand this high abortion rate. There are three major reproductive paths in Magnoliaceae: self-pollination, cross-pollination and apomixis. Different species have different reproductive methods. In the related species Manglietia pachyphylla, self-pollination from the same flower presents self-incompatibility, and it tends to be xenogamous [35]. Reproductive paths for Manglietia crassipes are not clear and need further study. 


\subsection{Suggestions for the Protection of Manglietia crassipes}

For the endangered status of $M$. crassipes, different papers have reported different opinions. In the "China Species Red List", M. crassipes was listed as a "critically endangered species" [4]. The publications such as "CHINA PLANT RED DATA BOOK-Rare and Endangered Plants (Volume 1)" [36] and the "List of National Key Protected Wild Plants (First Batch)" (http://www.gov.cn/gongbao/content/2000/content_60072.htm, accessed on 12 March 2019), did not treat it as a protected species. Based on our field surveys, $M$. crassipes was only distributed on Mount Dayao, in small, rare populations with less than 1000 individuals; thus the "critically endangered" status is most relevant. We suggest that this species should be treated as a grade I protected species in China.

Ex-situ conservation is an effective way to prevent $M$. crassipes from dying out. According to our results, $2500 \mathrm{mg} \cdot \mathrm{L}^{-1} \mathrm{GA}_{3}$ was the most efficient plant growth regulator for improving the \% seed germination GP, and GI. Before sowing, soaking seeds in $2500 \mathrm{mg} \cdot \mathrm{L}^{-1}$ $\mathrm{GA}_{3}$ was necessary for germination once collected from the wild. Once seeds have germinated, and seedlings have been grown outdoors, plants can be transferred to protected areas, such as botanical gardens. Guangxi Institute of Botany and Guangxi Medicinal Herb Garden are considered preferred places for growing seedlings of $M$. crassipes. The majority of one or two-year-old seedlings in the protected areas may then be returned to their original, or similar, habitats to increase the population. In addition, a seed bank for $M$. crassipes using $4{ }^{\circ} \mathrm{C}$ moist sand stratification is advised as the most efficient storage condition.

\section{Conclusions}

Fresh mature seeds of Manglietia crassipens in the wild have low germination rates. Physiological dormancy exists in seeds and $\mathrm{GA}_{3}$ can break dormancy. $\mathrm{GA}_{3}$ significantly improved germination rate and was best at $2500 \mathrm{mg} \cdot \mathrm{L}^{-1}$. 6-BA and IAA had different effects on seed germination, but the effects were slight. Germination viability of all stored seeds was obviously weakened. Using $4{ }^{\circ} \mathrm{C}$ moist seed stratification with sand is the recommended method for storing them for future propagation research.

Supplementary Materials: The following are available online at https:/ / www.mdpi.com/2311-7 524/7/3/42/s1, Table S1: Parameters of mature seed vigor under different treatments of GA 3 , 6BA, IAA. Table S2: Source of difference for the IGT through the Tests of Between-Subjects Effects. Dependent Variable: IGT. Table S3: Source of difference for the G through the Tests of BetweenSubjects Effects. Dependent Variable: G. Table S4: Source of difference for the GP through the Tests of Between-Subjects Effects. Dependent Variable: GP. Table S5: Source of difference for the GI through the Tests of Between-Subjects Effects. Dependent Variable: GI.

Author Contributions: Conceptualization, A.-H.W. and F.-G.W.; methodology, S.-G.C.; software, A.-H.W.; validation, Y.-Y.L. and X.-L.Y.; investigation and resources, S.-G.C.; formal analysis, A.-H.W. and S.-G.C.; writing-original draft preparation, A.-H.W.; writing-review and editing, F.-G.W.; funding acquisition, A.-H.W. All authors have read and agreed to the published version of the manuscript.

Funding: This research was funded by the "National Natural Science Foundation of China, grant number 30871960", and the "Natural Science Foundation of Guangxi Province, grant number 2018GXNSFBA138005".

Acknowledgments: We thank Qing-Wen Zeng, the professor of South China Botanical Garden, for his providing the detailed collection information of M. crassipes.

Conflicts of Interest: The authors declare no conflict of interest.

\section{References}

1. Xia, N.; Law, Y.; Hans, P.N. Magnoliaceae in Flora of China; 2008; Volume 7, pp. 52-61. Available online: http:/ / flora.huh.harvard. edu/china/mss/volume07/Magnoliaceae.pdf (accessed on 12 March 2019).

2. Law, Y. A new species of Magnoliaceae from Guangxi, China. Bull. Bot. Res. Harbin 1982, 2, $133-135$.

3. Law, Y.; Zeng, Q.W.; Zhou, R.Z.; Xing, F.W. Magnolias of China; Beijing Science and Technology Press: Beijing, China, 2004.

4. Wang, S.; Xie, Y. China Species Red List (Volume 1, Red List); Higher Education Press: Beijing, China, 2004. 
5. Ma, X.Y.; Jiao, G.L. The review on seed propagation of Magnoliaceae. Seed 2009, 10, 54-57. [CrossRef]

6. Ou, B. Research on nursery techniques and seedling growth rhythms of five varieties of Magnoliaceae. Jiangxi For. Sci. Tech. 2004, 6,7-9. [CrossRef]

7. Tang, A.J.; Long, C.L.; Dao, Z.L. Review on development of seed dormancy mechanisms. Acta Bot. Yunnanica 2004, 26, $241-251$. [CrossRef]

8. Bao, S.C.; Wu, J. Fruit harvest, seeds treatment, storage and screen of trees in Magnoliaceae. Mod. Agric. Sci. Technol. 2005, 17. [CrossRef]

9. Xu, B.H. Treatment and discern seeds of Magnoliaceae. Pract. For. Technol. 2005, 19-20. [CrossRef]

10. Du, F.G.; Wang, H.; Yang, D.M.; Liu, C.Q.; Sun, S.G.; Wang, Z.M. Morphology and Biological Characters of Seed of Magnolia sieboldii K. Koch. J. J. Beihua Univ. Nat. Sci. 2006, 7, 269-272. [CrossRef]

11. Fang, X.P.; Xu, J.; Yang, C.H.; Sun, J.C.; Xu, L.Y. Seed propagation of ornamental plants in Magnoliaceae. Seed 2006, 25, 54-56. [CrossRef]

12. Yu, D.L.; Wang, D.; Gao, L.H.; Zhang, T.H.; Zhao, X.B. Plant introduction and seedling raising technique of Magnoliaceae in the Xiong-yue arboretum. J. Liaoning For. Sci. Tech. 2007, 6, 61-62. [CrossRef]

13. Lai, J.Y.; Liu, J.B.; Pan, C.L.; Li, X.D. Effect of different treatments on the seed germination of Kmeria septentrionalis. Guangxi Sci. 2008, 2, 195-197. [CrossRef]

14. Lu, X.J.; Wang, N.N.; Li, T.L.; Han, Y.F.; Yang, J. Effect of different soaking and accelerating germination disposals on forced germination of Magnolia sieboldii seeds. J. Northwest A F Univ. (Nat. Sci. Ed.) 2008, 36, 135-140. [CrossRef]

15. Han, C.Y.; Long, C.L. Seed Dormancy, Germination and Storage Behavior of Magnolia wilsonii (Magnoliaceae), an Endangered Plant in China. Acta Bot. Yunnanica 2010, 32, 47-52. [CrossRef]

16. Han, C.Y.; Welbaum, G.; Long, C.L. Seed dormancy and germination of Michelia yunnanensis (Magnoliaceae). Sci. Hortic. 2009, 124, 83-87. [CrossRef]

17. Lu, X.; Mei, M.; Liu, Y.; Zhang, X.; Ma, B. Effect of treatment with GA3 and variable temperature stratification on germination and endogenous hormones of Magnolia sieboldii seeds. Acta Bot. Boreali-Occident. Sin. 2014, 34, 1828-1835. [CrossRef]

18. César, J.P.; Rosa, R.C.; Joel, F. Seed germination of Magnolia pugana (Magnoliaceae), an endemic and endangered species from Western Mexico. Bot. Sci. 2016, 94, 575-584. [CrossRef]

19. Iralu, V.; Upadhaya, K. Dormancy, storability, and germination of seeds in Magnolia punduana (Magnoliaceae). Botany 2016, 94, 967-973. [CrossRef]

20. Bai, H.J. Study on Propagation Techniques of Manglietia grandis. Master's Thesis, South China Agricultural University, Guangzhou, China, 2016. Available online: https:/ /CNKI:CDMD:2.1016.922349 (accessed on 12 March 2019).

21. Pan, R.; Sun, W.B. Seed dormancy and germination of the critically endangered Manglietia grandis Hu et Cheng. Plant Physiol. Commun. 2009, 45, 1089-1092. [CrossRef]

22. Li, Z.Y.; Xiao, J. Seed germination and physiological characters of Manglietia grandis. J. Northeast For. Univ. (Chin. Ed.) 2016, 3 , 37-41. [CrossRef]

23. Chen, F.; Liang, H.; Wang, X.; He, Z.; Li, F. Seed dormancy and germination characteristics of Manglietia patungensis, an endangered plant endemic to China. Biodivers. Sci. 2007, 15, 492-499. [CrossRef]

24. Zhang, D.; Zhang, B.; Liu, X.; Wang, X.; Chen, F. Seed isozyme analysis of Manglietia patungensis during storage and germination. Acta Bot. Boreali-Occident. Sin. 2011, 31, 1453-1457. [CrossRef]

25. Zuo, J.B. The analysis of seed characteristic of Michelia yunnanensis. Guizhou For. Sci. Technol. 1994, 2, $44-46$.

26. ISTA. International Rules for Seed Testing; Translated by National Crop Seed Quality Supervision and Testing Center in Ministry of Agriculture (China), and Seed Science Centre of Zhejiang University; China Agriculture Press: Beijing, China, 1996.

27. ISTA. International Rules for Seed Testing, 2008/1 ed.; ISTA: Bassersdorf, Switzerland, 2008; Volume 5.

28. Zhou, Y.X. Preliminary study on seeds dormancy and germination of Michelia chapensis. J. Cent. South Univ. For. Technol. 1990, 10, 165-170. [CrossRef]

29. Li, P.; Lu, X.J.; Yao, F.; Guo, R. Preliminary Study on Reasons of Seed Dormancy of Magnolia sieboldii K. Koch. Seed 2006, 25, 36-39. [CrossRef]

30. Lu, X.J.; Li, T.L.; Ni, W.D. Study on the dormant characteristic of M. sieboldii K. Koch seeds. J. Shenyang Agric. Univ. 2006, 37, 703-706. [CrossRef]

31. Fu, X.Y.; Yu, G.Y.; Zhou, G.Z. Reasons of dormancy for seeds of Magnolia obovata. Liaoning For. Sci. Tech. 2008, 1, 1-3/9. [CrossRef]

32. Zheng, Y.L.; Sun, W.B.; Zhao, X.F. Seed dormancy and germination of Manglietiastrum sinicum Law, a globally critical endangered plant in China. Plant Physiol. Commun. 2008, 44, 100-102. [CrossRef]

33. Fernando, M.T.R.; Jayasuriya, K.M.G.; Walck, J.L.; Wijetunga, A.S.T.B. Identifying dormancy class and storage behaviour of champak (Magnolia champaca) seeds, an important tropical timber tree. J. Natl. Sci. Found. Sri Lanka 2013, 41, 141-146. [CrossRef]

34. Zhao, X.J.; Tan, D.Y. Selective abortion and its evolutionary, ecological significance in seed plants. Chin. J. Plant Ecol. 2007, 31, 1007-1018. [CrossRef]

35. Yang, X.L. Study on the Conservation Biology of the Endangered Plant Manglietia pachyphylla; South China Botanical Garden: Guangzhou, China, 2013.

36. Fu, L.G.; Jin, J.M. China Plant Red Data Book—Rare and Endangered Plants (Volume 1); Science Press: Beijing, China, 1992. 